\title{
Teaching and Management of Power Electronics Course Based on Curriculum Group Model
}

\author{
Gao Shengwei $^{\mathrm{a}}$, Li Longnv ${ }^{\mathrm{b}}$, Liu Xiaoming ${ }^{\mathrm{c}}$ and Wang Qiqi ${ }^{\mathrm{d}}$ \\ Key Laboratory of Advanced Electrical Engineering and Energy Technology Tianjin 300387 China \\ aemail: gaoshengwei@tjpu.edu.cn, bemail: lilongnv@tjpu.edu.cn, 'email: liuxiaoming@tjpu.edu.cn, \\ demail: 1135988149@qq.com
}

Keywords: Power Electronic Technology, Curriculum Group, Construction, Teaching, Management

\begin{abstract}
To meet the social demand for talent level, to adapt to the needs of professional construction of higher education in china, it is an inevitable trend to carry out the construction of curriculum group in the professional construction of higher education institutions. The organization division of curriculum group plays a key role in the construction and practice of the teaching management system. In this paper, the course group of power electronics technology has been proposed. Reform method has been discussed in teaching content, teaching outline, examination method and solving complicated engineering problem. The course group of power electronics technology can eventually be built based on the close contact with the actual and scientific management. The teaching level of the course group is also the overall teaching level.
\end{abstract}

\section{Introduction}

With the development of economy, the demand for power electronics technology is growing rapidly. The cultivation of talents has attracted wide attention. But the existing teaching content of power electronics and related courses cannot meet the needs of society. Therefore, it is urgent to construct the curriculum group to improve the teaching quality and course management level. Curriculum group is a collection of several courses. At present, some colleges and universities have been carrying out curriculum construction, curriculum system construction, but also carried out the curriculum group construction in China.

At present, some colleges and universities are not only carrying out curriculum construction and curriculum system construction, but also to carry out the curriculum group construction. And it will become the new trend of teaching reform and research in colleges and universities. In this paper, the connotation of the curriculum group, the construction and management of the curriculum group and other issues have been discussed. And taking the construction of power electronics technology curriculum group as an example, the solution to the key problems of the curriculum structure, teaching outline, assessment method and ability cultivation has been proposed.

\section{The Basic Connotation of the Curriculum Group Construction}

Relevance and integration is the basic connotation of the curriculum group. The relevance refers to the curriculum group as a new teaching management system. It can break the attribution of curriculum content, weaken the independence of curriculum, strengthen the affinity between courses to make them coherent in a higher level [1]. The integration refers to the re-planning, design, fill the gap between the original course. By removing duplicate content from the original course, the students can better learn a course, and can better grasp the relationship between the entire curriculum group. In this way, it is possible to achieve the effect that the overall harvest is greater than the sum of the parts. It is the design principle of the curriculum group that related and succession, convergence and cooperation, interactive and orderly, infiltration and complementarity. The relationship diagram has been shown in Figure 1. 


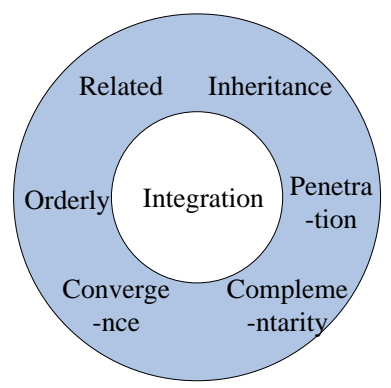

Fig. 1. Connotation of curriculum group

\section{Necessity Analysis and Implementation of Curriculum Group}

As shown in Figure.2, a lot of problems should be faced for each course in the implementation process.

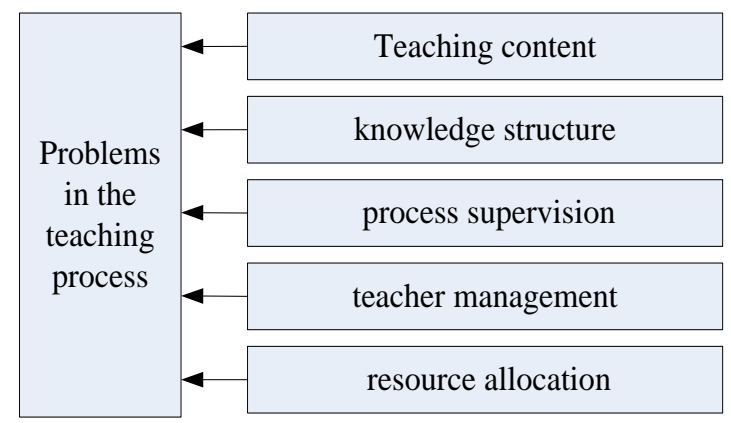

Fig.2. Problems in the construction of curriculum group

The effort to solve problem of a course curriculum is narrow, and does not help. Better solutions can be proposed by sorting out and studying these issues from the whole. So the building of curriculum group is very necessary.

When the "curriculum group" model is adopted, the independence of the course can be weakened, and the connection between the courses is becoming more and more interdependent. Especially when the graduation requirement of student has been achieved by the curriculum group, teaching effectiveness will be placed first in all aspects of the curriculum group system [2]. Therefore, the implementation of curriculum group teaching system can conducive to improving the quality of teaching and student quality.

Table.1 Curriculum group construction

\begin{tabular}{|c|c|}
\hline Target & \multicolumn{1}{c|}{ Implementation Method } \\
\hline $\begin{array}{c}\text { Content } \\
\text { Science }\end{array}$ & $\begin{array}{c}\text { There is a clear relationship between the pre-course and the following course, } \\
\text { which makes it easy to organize teaching. The content of course in the curriculum } \\
\text { group should be related, close, progressive. }\end{array}$ \\
\hline $\begin{array}{c}\text { Structure } \\
\text { orderly }\end{array}$ & $\begin{array}{c}\text { Theoretical courses, supporting the experimental class, integrated practical } \\
\text { courses should be included in most courses in the curriculum group }\end{array}$ \\
\hline $\begin{array}{c}\text { Process } \\
\text { controllable }\end{array}$ & $\begin{array}{c}\text { Knowledge points, difficulty levels, teaching requirements, support graduation } \\
\text { requirements must be given. Each teacher should strictly enforce the standards in the } \\
\text { teaching process. The arbitrary in teaching should be overcome. }\end{array}$ \\
\hline $\begin{array}{c}\text { Teachers } \\
\text { reasonable }\end{array}$ & $\begin{array}{c}\text { Make good use of existing talent, training reserve personnel, the introduction of } \\
\text { much-needed talent. To achieve the overall upgrade and enrichment in Teachers. }\end{array}$ \\
\hline $\begin{array}{c}\text { Resource } \\
\text { Sharing }\end{array}$ & $\begin{array}{c}\text { Full use of digital resources, network resources. Create public numbers and } \\
\text { websites on multimedia tools to attract students to participate and share }\end{array}$ \\
\hline
\end{tabular}

The method of based on curriculum group model teaching and management can simplify the teaching process. And the more explicit teaching objectives can be established [3]. The content of 
courses in the curriculum group can be more closely in teaching and practice. It can help students to expand their knowledge and skills in teaching and then train and truly master the ability of students from all aspects.

\section{Construction Program of Power Electronics Curriculum Group}

The course of power electronic is a specialized foundation course in the electrical engineering. It is a bridge between basic and specialized courses in the teaching system. It has played a leading role in professional courses. Through the establishment of power electronics technology curriculum group, the professional curriculum construction and the reform of the entire curriculum system can be promoted.

Course Structure and Integration. "Power electronic technology" "electric drive automatic control system" "modern power technology" and "Microcontroller Principles and Applications" are more mature and classic. In opening of the courses, the content of courses must be extended and expanded in knowledge for the sake of the integrity of their own system. Since there is no overall co-ordination of curriculum groups, the duplication of some content is unavoidable as shown in Figure.3. So the teaching idea is not clear, the teaching efficiency is low, the learning effect is poor.

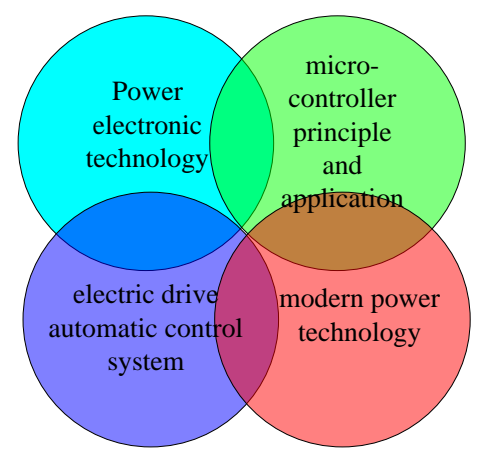

Fig.3. Course relationships in the absence of curriculum groups

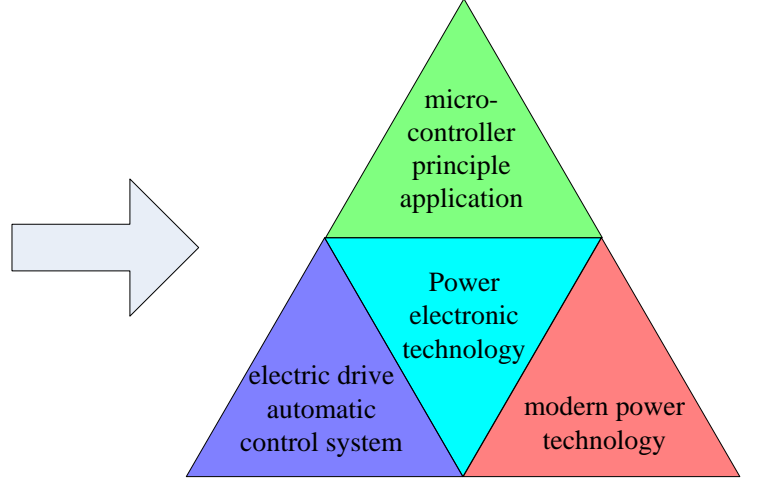

Fig.4. Curriculum group model

In the implementation of integration, the resources of teaching can be unified coordination organization, and the barriers of courses, experiment and teachers can be broken. "Power electronic technology" is the core of curriculum group model [4]. The electric "drive automatic control system", "modern power technology" are the extension of the core curriculum. Practice teaching of "Microcontroller Principles and Applications" can fill the shortcoming of practical control application of power electronics technology. The curriculum group model of "Power electronics technology" curriculum group model has been shown in Figure 4. Relevance and integration have been demonstrated in curriculum group model. Curriculum structure and teaching ideas have been highlighted. The ability to access to new knowledge and apply new knowledge can be effectively developed. The quality of students can be comprehensively improved.

Syllabus Adjustment. It is the most important features of the curriculum group construction that the teaching content optimization and integration. Simultaneously, repeated content can be compressed, mutual support relationship can be strengthened, learning efficiency can be improved. The course of "Power Electronics Technology" covers the content of the structure, basic principle, driving method, driving circuit and device selection of power electronic device and working principle, design and calculation method of power electronic circuit [5]. The course of "Electric drive automatic control system" covers the content of application and control method of power electronic circuit. The basic principles and control methods of SPWM can be introduced in this course. The course of "Modern Power Supply Technology" covers the content of DC / DC, AC / DC, DC / AC converter and soft switching. Therefore, the construction of the curriculum group should be based on the requirements of the latest undergraduate training program and the current development of various disciplines. According to the latest undergraduate training program 
requirements and the current development of various disciplines, curriculum group can be built. Through a detailed examination of the course content, the syllabi of course can be revised.

Variety of Assessment Methods. By examinations, the teaching effects can be checked and the purpose of teaching can be measured. But it has been proved by the research that the enthusiasm of students cannot be fully mobilized by an examination, learning results of the student cannot be fully evaluated. The learning outcomes of students can be examined through uninterrupted multiple forms of evaluation. Students can be supervised through a variety of assessment forms. For example, the proportion of normal results should be increased in the total score. The results of a student's study can be included in the total grade of the course. The usual assessment includes: homework, classroom questions, discussions, reports and periodic tests and so on. Through these methods, the real achievements and comprehensive abilities of the Students can be fully reflected. At the same time, with the rapid development of science and technology, multimedia technology can be applied to teaching is an inevitable trend. The Mobile WeChat and Public Number are good means of communication with students. As shown in Figure.5. The learning element has been injected when they hold mobile phones.
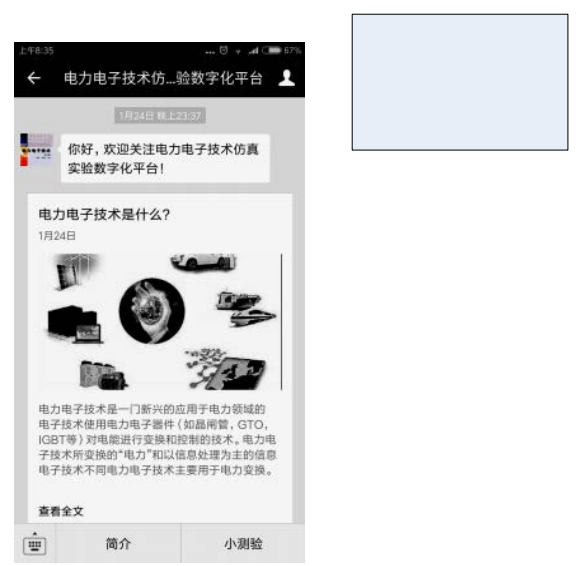

Fig.5. Public number of power electronic technology curriculum group in phone

Design of Complex Engineering. In Figure.6 PCS (Partition Control Signal), PC (Partition Controller), F (Filter), C(Controler), L(Loader), G(Generator).

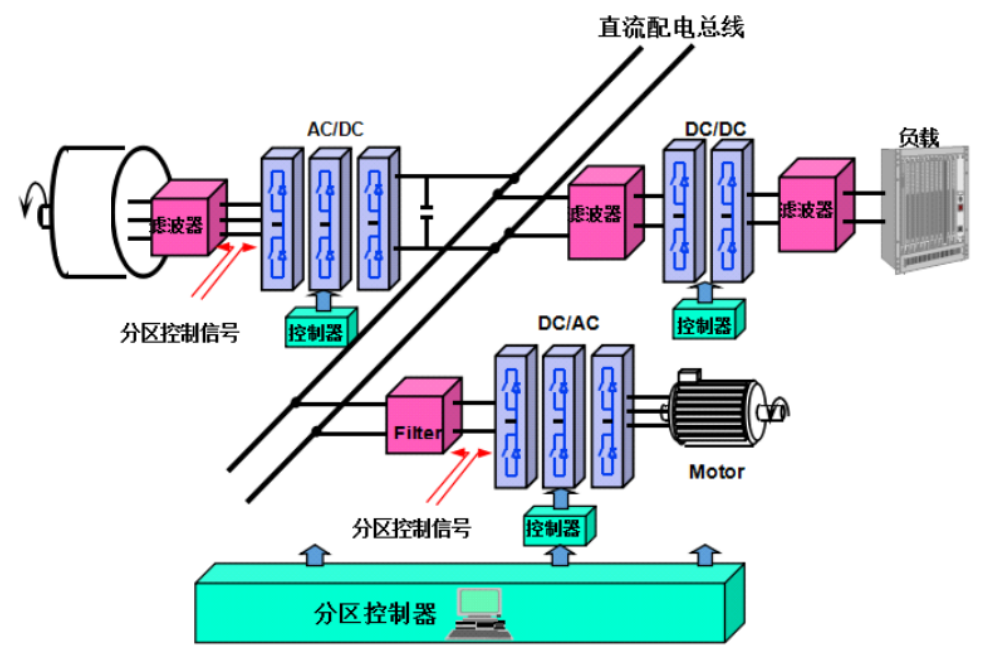

Fig.6. Examples of complex engineering problems in electrical engineering

The analysis and application of power device and physical system is the essence of "power electronics" curriculum group. A typical complex engineering problem model for electrical specialties has been shown in the Figure.6. The knowledge of multiple courses has been included in the model. Participation of the various courses is the key to cultivating competence in solving complex engineering problems [6]. The key links and problem-solving methods can be reflected in each of the individual courses. The key links and problem-solving methods should be reflected in 
each of the individual courses. The knowledge can be tandem into a whole, when the course in the curriculum group has been completed. And the complex engineering problem model can be controlled and the solution to the problem can be presented.

\section{Conclusion}

The connotation, the necessity and the construction method of the curriculum group, has been discussed in this paper. The methods has been discussed about "power electronics" curriculum group on the courses integration, syllabus construction, assessment adjust and solve the problem of complex engineering capacity training. In this paper, the teaching reform method of the course group has been put forward. At the same time, the construction of curriculum group about the power electronics course has accumulated experience for other curriculum group construction in electrical engineering.

\section{Acknowledgement}

In this paper, the research was sponsored by the National Engineering Graduate Education Steering Committee, Graduate Teaching Reform (Project No. 2016-ZX-059); National Engineering Graduate Education Steering Committee, Graduate Teaching Reform (Project No. 2016-ZX-063); Tianjin University of Technology, Graduate Education Reform Research Project "Based on a Wide Range of Postgraduates Open Power Electronic Technology Teaching Platform" and Ministry of Education, College of Electrical Engineering Steering Committee Teaching Reform (Project No. DQJZW2016017).

\section{References}

[1] Zhao Xia Gou. Research on University Network Teaching Platform (Blackboard) in Teaching Management. [C]. MATEC Web of Conferences. 12(2016)55-58.

[2] Hansen, Poul Kyvsgaard. Engineering Case Method Applied in Teaching Modularization Management. [J]. Proceedings of Nord Design 2016, Trondheim Norway. 2(2016) 198-207.

[3] Lew, Moi Mooi. New Teachers' Challenges: How Culturally Responsive Teaching, Classroom Management, \& Assessment Literacy Are Intertwined. [J]. Multicultural Education; San Francisco. 23 (2016) 7-13.

[4] Justin G. Peacock. An online app platform enhances collaborative medical student group learning and classroom management. [J]. Medical Teacher.3(2015) 174-180.

[5] Bao Xun. Research on the Intelligent Information System for the Multimedia Teaching Equipment Management. [C]. 2016 International Conference on Information System and Artificial Intelligence. 5(2016) 128-132.

[6] Run Zhu. Experimental Center Construction of Teaching Management Platform Under the Background of Digital Campus. [C]. 2016 Eighth International Conference on Measuring Technology and Mechatronics Automation. 6(2016) 286-289. 